\title{
Tigecycline: an evidence-based review of its antibacterial activity and effectiveness in complicated skin and soft tissue and intraabdominal infections
}

\author{
Christopher J. Dunn
}

Catalyst Communications Ltd, Auckland, New Zealand

\begin{abstract}
Introduction: There is an urgent need for novel agents to manage serious bacterial infections, particularly those contracted in healthcare facilities. Tigecycline is a novel broad-spectrum glycylcycline with good activity against Gram-positive, many Gram-negative, anaerobic, and some atypical pathogens that has been developed to address this need.

Aims: To review the evidence for the use of tigecycline in serious and complicated skin and soft tissue and intraabdominal infections.

Evidence review: There is substantial evidence that tigecycline is as effective as vancomycin plus aztreonam in complicated skin and skin structure infections (SSSIs) and as effective as imipenem plus cilastatin in intraabdominal infections. Limited evidence shows effectiveness in patients with resistant Acinetobacter infection in an intensive care unit, and the possibility that the use of tigecycline may reduce length of hospital stay. The drug is well tolerated, with nausea and vomiting as the major adverse effects.

Outcomes summary: The introduction of tigecycline should be beneficial at a time of increasing problems with bacterial resistance, and evidence to date has been sufficient for regulatory approval for complicated SSSIs and intraabdominal infections. Research into tigecycline's efficacy in other infectious diseases (notably pneumonia and bacteremia) is ongoing. Further good quality studies and ongoing surveillance for any emerging bacterial resistance will be needed to determine outcomes with tigecycline relative to other novel antibacterial agents, and to explore the economic implications of its adoption.
\end{abstract}

Key words: antibiotic resistance, bacterial infections, glycylcycline, nosocomial infections, review, tigecycline

Core evidence outcomes summary for tigecycline in complicated skin and soft tissue and intraabdominal infections

\begin{tabular}{|c|c|c|}
\hline Outcome measure & Evidence & Implications \\
\hline \multicolumn{3}{|l|}{ Patient-oriented evidence } \\
\hline Good patient acceptability & Substantial & $\begin{array}{l}\text { Good chance of success in severe infections without poor tolerability characteristic of } \\
\text { some older antibacterials }\end{array}$ \\
\hline $\begin{array}{l}\text { Avoidance of morbidity or mortality due to empiric } \\
\text { treatment failure in the most seriously ill patients }\end{array}$ & Limited & $\begin{array}{l}\text { Patients needing intensive care and/or infected with multiresistant pathogenic strains } \\
\text { resistant to other available antibacterials may respond to tigecycline. Further studies } \\
\text { required }\end{array}$ \\
\hline \multicolumn{3}{|l|}{ Disease-oriented evidence } \\
\hline $\begin{array}{l}\text { Clinical cure in complicated skin and soft tissue and } \\
\text { intraabdominal infections }\end{array}$ & Substantial & $\begin{array}{l}\text { Effective in these infections, but superiority over other antibacterials in terms of response } \\
\text { rates has not yet been demonstrated }\end{array}$ \\
\hline $\begin{array}{l}\text { Microbiologic eradication in patients infected with a } \\
\text { range of Gram-positive and Gram-negative } \\
\text { organisms }\end{array}$ & Substantial & $\begin{array}{l}\text { Is likely to be widely effective in a range of patients with serious and difficult infections } \\
\text { resistant to other agents }\end{array}$ \\
\hline \multicolumn{3}{|l|}{ Economic evidence } \\
\hline More rapid discharge from hospital & Limited & $\begin{array}{l}\text { Has considerable implications for both patient wellbeing and health economics; level } 2 \\
\text { evidence required }\end{array}$ \\
\hline $\begin{array}{l}\text { Acquisition cost offset or incremental cost } \\
\text { effectiveness/benefit }\end{array}$ & No evidence & $\begin{array}{l}\text { Dependent on maintenance of clinical effectiveness and avoidance of empiric treatment } \\
\text { failure. Studies are required }\end{array}$ \\
\hline
\end{tabular}




\section{Scope, aims, and objectives}

This evidence-based review of the activity and clinical effectiveness of tigecycline, the first of the novel glycylcycline class of antibiotics, focuses on the use of the drug in complicated and serious skin and soft tissue and intraabdominal infections known to pose resistance problems with current therapy and associated with or requiring treatment in healthcare facilities.

The emergence of microorganisms resistant to current antibacterial agents is a matter of concern, particularly in patients with serious, complicated, and nosocomial infections. Virtually all common infectious bacteria have developed resistance to at least one class of antibiotics, and tigecycline has been developed as part of the effort to identify novel antibacterial agents in the face of the growing problem, particularly in hospitals, of potentially lifethreatening multiresistant organisms and polymicrobial infections. A number of agents are available for the treatment of conditions of chief concern, including skin and intraabdominal infections (particularly those contracted in hospitals) and pneumonia, but available antibacterials have been widely affected by resistance, and some older agents used for serious infections (e.g. vancomycin) may be poorly tolerated by some patients. New drugs that have recently been introduced into clinical practice have been aimed mainly at multiresistant Gram-positive infections, but early resistance to, for example, the novel oxazolidinone linezolid (Mutnick et al. 2003; Halle et al. 2004; Meka et al. 2004) and the cyclic lipopeptide daptomycin (Mangili et al. 2005; Sabol et al. 2005) has already been reported. New agents that target broad ranges of both Gram-positive and Gram-negative organisms, particularly the emerging extended spectrum betalactamase (ESBL) producers, anaerobes, and methicillin- and/or oxacillin-resistant Gram-positive isolates, are urgently needed.

Tigecycline is one of a number of drugs under development with these needs in mind, and is designed to circumvent two of the most common resistance mechanisms, efflux and ribosomal protection. It is a semisynthetic derivative of minocycline that is mechanistically similar to the aminoglycosides, macrolides, streptogramins, and oxazolidinones in that it binds to the $30 \mathrm{~S}$ ribosomal subunit (Chopra 2001; Guay 2004; Zhanel et al. 2004). This blocks access of aminoacyl tRNA to its acceptor site and leads to the prevention of bacterial protein synthesis and growth. Examination and review of tigecycline is timely because, at the time of writing, two phase III trials have been completed with several others underway, and Food and Drug Administration (FDA) approval has been granted in the USA (Anon. 2005).

\section{Methods}

The English language medical literature was searched for appropriate articles relating to tigecycline. The following databases were searched on June 16, 2005, and again on November 11, 2005, with the search terms "tigecycline OR GAR-936," and no date limits:

- PubMed, http://www.ncbi.nlm.nih.gov/entrez

- EMBASE and BIOSIS, http://www.datastarweb.com
- Database of Abstracts of Reviews of Effects (DARE), National Health Service Economic Evaluation Database (NHSEED), Health Technology Assessment (HTA), http://www.york.ac.uk/inst/crd/crddatabases.htm

- Cochrane Database of Systematic Reviews (CDSR), http://www.cochrane.org

- Clinical Evidence (BMJ), http://www.clinicalevidence.com

- National Institute for Health and Clinical Excellence (NICE), http://www.nice.org.uk

- National Guidelines Clearing House, http://www.guideline.gov

The following websites were also searched for information including details of recent meetings (since 2003) hosted by societies specializing in medical microbiology:

- The annual congress of the European Society of Clinical Microbiology and Infectious Diseases (ESCMID), http://www.escmid.org

- The annual Interscience Conference on Antimicrobial Agents and Chemotherapy (ICAAC), http://www.icaac.org

- The Federation of European Microbiological Societies (FEMS), http://www.fems-microbiology.org

- The Infectious Diseases Society of America (IDSA), http://www.idsociety.org

Table 1 summarizes the levels of evidence for articles identified from the search strategy. The original search (June 2005) yielded 89 full papers, of which one was included as level 3 evidence. Two of four level 2 studies were available in abstract form only at that time. Updated searching (November 2005) yielded subsequent full publications of these articles, together with one further paper and an additional full report not included in the databases searched but provided by the company developing tigecycline (Table 1).

There are currently no systematic reviews on tigecycline, and there is a good deal of information on the drug that relates to its antimicrobial activity in vitro and in animal models. These references, together with nonsystematic general review articles in which tigecycline featured, were excluded from the 132 full papers identified. This left one fully published phase II study (level 3 evidence) and four phase III trials (level 2 evidence). Five studies available as meetings abstracts were also identified (from websites of major professional bodies and meetings as above) at the time of writing. One of these provided level 3 (phase II) evidence, one level 5 (a small case series from a single center), and three were economic studies classified as level 3 evidence.

\section{Disease overview}

The development of tigecycline and other novel antibacterials currently under investigation is aimed chiefly at the problems 
Table 1 | Evidence base included in the review

\begin{tabular}{|lcc|}
\hline Category & \multicolumn{2}{c|}{ Number of records } \\
\cline { 2 - 3 } & Full papers & Abstracts \\
\hline Initial search & 132 & 74 \\
records excluded & 128 & 70 \\
records included & 4 & 4 \\
Additional studies identified & 1 & 1 \\
Total records included & 5 & 5 \\
Level 1 clinical evidence & 0 & 0 \\
Level 2 clinical evidence & 4 & 0 \\
Level $\geq 3$ clinical evidence & 1 & 2 \\
trials other than RCT & 1 & 1 \\
case studies & 0 & 1 \\
Economic evidence & 0 & 3 \\
\hline For definition of levels of evidence, see Editorial Information on inside back cover. \\
RCT, randomized controlled trial.
\end{tabular}

caused by resistant or complicated infections, with particular emphasis on those contracted in healthcare facilities. It is worth noting that, in the USA alone, nosocomial infections affect around 2 million persons admitted to hospitals for acute care each year (Anon. 2000). Many of these infections are caused by multiresistant Gram-positive and Gram-negative pathogens, and their incidence continues to increase because of failure of hospital hygiene procedures, selective pressures resulting from inappropriate use and overuse of antibiotics, and other factors that can lead to the encoding of bacterial resistance mechanisms.

The costs associated with managing infections are clearly considerable. While it is difficult to estimate the global burden on healthcare systems of infective disease, some helpful indicators were provided in the 1990s by the UK Public Health Laboratory Service (Plowman 2000), which examined the socioeconomic consequences of hospital-acquired infection (HAl). Patients who presented with one or more HAls during an inpatient stay incurred costs 2.9 times greater than those for uninfected patients. This represented an absolute increase of $£ 3154$ per case in the 1449 patients selected for follow-up in this study. On average, the length of hospital stay was 2.9 times (14 days) longer for patients with an $\mathrm{HAl}$, and additional burdens were imposed on community healthcare services after discharge. The overall cost of HAls to the UK National Health Service was estimated as £986.36 million.

Diseases of particular concern include the frequently encountered skin and skin structure infections (SSSIs) and intraabdominal infections. SSSIs are caused chiefly by Gram-positive organisms, and are increasing in incidence mainly because of aging of the general population, increases in the numbers of critically ill and immunocompromised patients, and the emergence of multiresistant pathogens. SSSIs include simple and uncomplicated or superficial infections such as erysipelas, cellulitis, simple abscesses, furuncles, and wound infections, but also encompass complicated and more serious disorders such as necrotizing fasciitis, myositis, and gas gangrene. In general, an
SSSI is considered complicated if it involves structures beneath the skin, such as fascia or muscle, requires significant surgical intervention, or accompanies disorders such as diabetes mellitus or human immunodeficiency virus (HIV) infection. Common pathogens are Staphylococcus aureus, Streptococcus pyogenes, Str. agalactiae, and group C and G streptococci [see the full review on this subject by Raghavan \& Linden (2004)].

Data from England and Wales indicate further the increasing scale of the problem of multiresistant infections. Crowcroft and Catchpole (2002) examined death registrations from 1993 to 1998 and found an increase in the proportion of certificates mentioning methicillin-resistant Staph. aureus (MRSA) from 7.5\% in 1993 to $25 \%$ in 1998 . The authors stated that improved rates of reporting were unlikely to explain this increase, and found the greatest rise in MRSA rates to be associated with death in which invasive staphylococcal infection was given as the final underlying cause.

Group D streptococci include the enterococci Enterococcus faecalis, Ent. durans, and Ent. faecium; these microorganisms cause endocarditis, urinary tract infections, intraabdominal infections, cellulitis, wound infections, and bacteremia. Enterococci are intrinsically resistant to many antimicrobial agents including cephalosporins, penicillins, cotrimoxazole, and clindamycin (Kauffman 2003). Since 1989, however, rapid increases in the incidences of infection and colonization with vancomycin-resistant enterococci (VRE) have been reported (Anon. 1995). Increased risk of VRE infection is associated with previous vancomycin or multiple antimicrobial therapy, severe underlying disease, or abdominal surgery (Anon. 1995). Enterococci can also be spread by direct or indirect contact within institutions, and between hospitals by contaminated personnel (Kauffman 2003).

\section{Current therapy options}

Although the treatment of complicated, resistant, and/or nosocomial infections varies in accordance with national recommendations and local infection control guidelines, generally applicable prescribing information can be found in recent reviews and official guidelines from the UK and USA. It is obviously not possible to present a comprehensive review of current antiinfective prescribing practice here, but a representative picture can be drawn by focusing on the agents currently in use for treating SSSIs and intraabdominal infections.

Current UK recommendations for skin and gastrointestinal infections can be found in the British National Formulary, and are summarized in Table 2 (BNF 2005). It should be noted that the general principals of antibiotic prescribing apply in all cases: benzyl- or phenoxymethylpenicillin is recommended for streptococcal infection, with the addition of flucloxacillin where staphylococcal infection is suspected, or a macrolide for atypical infection (e.g. Mycoplasma or Chlamydia spp.). Topical mupirocin may be effective against MRSA. Peritonitis and related infections are covered generally by a cephalosporin or gentamicin with metronidazole or clindamycin. 
Table 2 | UK prescribing recommendations for skin and gastrointestinal infections (BNF 2005)

\begin{tabular}{ll} 
Condition & Recommended treatment \\
\hline Skin infections & \\
Cellulitis & Benzylpenicillin + flucloxacillin (or erythromycin alone if penicillin - a \\
Gastrointestinal system & \\
Campylobacter enteritis & Ciprofloxacin or erythromycin \\
Invasive salmonellosis & Ciprofloxacin or trimethoprim \\
Shigellosis & Ciprofloxacin or trimethoprim \\
Pseudomembranous colitis & Metronidazole or vancomycin \\
Biliary tract infection & Cephalosporin or gentamicin \\
Peritonitis & Cephalosporin (or gentamicin) + metronidazole (or clindamycin)
\end{tabular}

Comprehensive diagnostic and prescribing guidelines have been published in the USA for SSSIs (Stevens et al. 2005) and intraabdominal infections (Solomkin et al. 2003) by IDSA. Broadly, a penicillinase-resistant semisynthetic penicillin or first generation cephalosporin is recommended for cellulitis, with clindamycin or vancomycin being suggested for patients allergic to penicillin. For severe group A streptococcal and clostridial necrotizing infections, parenteral clindamycin and penicillin therapy is recommended, with a variety of single agents indicated for aerobic Gram-positive and Gram-negative infections as well as for anaerobes (see Table 3). SSSIs caused by community-acquired MRSA may be susceptible to nonbeta-lactam antibiotics such as doxycycline, clindamycin, trimethoprim/sulfamethoxazole, quinolones, or rifampicin. Severe infections that require hospitalization and that have not responded to other interventions can be treated with linezolid, daptomycin, or vancomycin. Trimethoprim/sulfamethoxazole has also been used to treat serious staphylococcal infections (Stevens et al. 2005).

Reviewers of recent developments in antiinfective therapy have recommended antistaphylococcal penicillins (e.g. nafcillin, oxacillin) or cefazolin for simple community-acquired SSSIs (Raghavan \& Linden 2004). Nosocomial infections, on the other hand, may be treated with a semisynthetic penicillin such as piperacillin/tazobactam with or without vancomycin or teicoplanin. Vancomycin and teicoplanin are preferred for suspected MRSA. Oral switching to linezolid can take place after

\section{Table 3 | Examples of US prescribing recommendations for skin and skin structure and intraabdominal infections (Solomkin et al. 2003; Stevens et al. 2005)}

Condition

Recommended treatment

Skin and skin structure infections

Cellulitis or erysipelas

Dicloxacillin, cephalexin, clindamycin, or erythromycin. Parenteral therapy in severely ill patients/unable to take oral medication: nafcillin, cefazolin, clindamycin, or vancomycin MRSA (hospital): linezolid, daptomycin or vancomycin. Also trimethoprim/sulfamethoxazole, or quinolone with good Gram-positive activity

Necrotizing infections of skin, fascia, and muscle

Surgical site infections

\section{Intraabdominal infections}

Mild to moderate community-acquired infections

Healthcare-acquired infections
Mixed infection: ampicillin/sulbactam or piperacillin/tazobactam plus clindamycin plus ciprofloxacin. Also imipenem/cilastatin, meropenem, ertapenem, or cefotaxime plus metronidazole or clindamycin Streptococcal infection: penicillin plus clindamycin

Staphylococcus aureus: nafcillin, oxacillin, cefazolin, vancomycin, or clindamycin

Clostridial infection: clindamycin or penicillin

Intestinal/genital tract, single agents: cefitoxin, ceftizoxime, ampicillin/sulbactam, ticarcillin/clavulanate, piperacillin/tazobactam, imipenem/cilastatin, meropenem, or ertapenem

Intestinal/genital tract, combination: quinolone, third generation cephalosporin, aztreonam, aminoglycoside (facultative and aerobic activity). Clindamycin, metronidazole, chloramphenicol, penicillin + beta-lactamase inhibitor (anaerobic activity)

Nonintestinal: oxacillin, first generation cephalosporin (trunk and extremities). Cefoxitin, ampicillin/sulbactam, other single agents as above for intestinal/genital operations (axillary or perineal)

Ampicillin/sulbactam, cefazolin or cefuroxime/metronidazole, ticarcillin/clavulanate, or ertapenem Aminoglycoside (first choice for empiric use; completion with oral quinolone plus metronidazole or oral amoxicillin/clavulanate) 
early discharge of hospitalized patients with MRSA. Nosocomial Gram-negative infections can be treated with an antipseudomonal penicillin plus an aminoglycoside, and carbapenems are recommended for ESBL-producing Gramnegative pathogens (Raghavan \& Linden 2004).

For patients with community-acquired intraabdominal infections, IDSA recommends the use of agents with narrower spectra of activity that are not commonly used for nosocomial infections. These include ampicillin/sulbactam, cefazolin or cefuroxime plus metronidazole, ticarcillin/clavulanate, ertapenem, and a quinolone plus metronidazole. For patients with more serious infections, alternatives include meropenem, imipenem/cilastatin, third or fourth generation cephalosporins plus metronidazole, ciprofloxacin plus metronidazole, or piperacillin/tazobactam (see also Table 3). The more resistant flora associated with nosocomial intraabdominal infections require treatment with more complex multidrug regimens (Solomkin et al. 2003). It should be noted here that these and other guidelines for antiinfective therapy are subject to ongoing revision as novel agents are developed and infection and resistance patterns change.

A number of novel antibacterial agents have been introduced in recent years or are under current development. The major drugs of interest are discussed in more detail in the following section and are summarized in Table 4.

\section{Unmet needs}

Resistance to conventional antiinfective agents and the continuing emergence of multiresistant organisms in healthcare institutions are currently major concerns for researchers and clinicians. Indeed, the IDSA is sufficiently worried about these problems to have endorsed the introduction of legislation in the US Senate to encourage the development of new antiinfectives, and is currently urging its members to lobby Congress (IDSA 2005a). Key issues identified by IDSA include the "drying up of the pipeline of new antibiotics," and a loss of momentum in antibiotic research because of cost and regulatory factors, time constraints, and reduced profitability relative to other disease areas (IDSA 2005b).

Epidemiologic data underline the reasons for these concerns. High or intermediate resistance to penicillin is exhibited by $50 \%$ of pneumococcal strains in the USA, and similar numbers of Staph. aureus isolates are resistant to methicillin (Wenzel 2004). Of the enterococci, $30 \%$ are resistant to vancomycin, and $20 \%$ of strains of Pseudomonas aeruginosa are resistant to quinolones and $15 \%$ to imipenem. A recent large survey of 670 US hospitals has shown resistance rates for oxacillin-resistant Staph. aureus (ORSA), VRE, quinolone-resistant Escherichia coli, and ESBLproducing Klebsiella spp. to be $36,10,6$, and $5 \%$, respectively (Diekema et al. 2004). These rates were reported to be on the increase in the majority of hospitals.

Several research initiatives have been underway in recent years, however, to identify new antiinfective agents. These efforts have resulted in the introduction of a number of new drugs, most of which are aimed at Gram-positive infections. These agents are represented most prominently by the oxazolidinone linezolid and the cyclic lipopeptide daptomycin.

Linezolid has a comprehensive spectrum of activity against the major nosocomial Gram-positive pathogens, including those with multiresistant phenotypes, and can be given either parenterally or orally (Kauffman 2003; Raghavan \& Linden 2004). However, as mentioned above, early resistance to linezolid has already been reported (Mutnick et al. 2003; Halle et al. 2004; Meka et al. 2004), notably in staphylococcal and enterococcal isolates. Other oxazolidinones are in early clinical development (Gravestock 2005).

Daptomycin has a mode of action that is not completely understood but that involves cell membrane binding and potassium efflux. The drug is rapidly bactericidal against most Gram-positive pathogens, which may have importance in the treatment of endocarditis and meningitis. Daptomycin has also

Table 4 | Major new antimicrobial agents under development or recently introduced for nosocomial or resistant infections (adapted from Raghavan \& Linden 2004)

\begin{tabular}{|c|c|c|c|}
\hline Drug & Class & Susceptible organisms & Resistance \\
\hline Linezolid & Oxazolidinone & $\begin{array}{l}\text { MSSA, group A, B, C, F, G, and viridans } \\
\text { streptococci, CoNS, MRSA, GRSA, GISA, VRE, } \\
\text { VRSA, PRSP, corynebacteria, Listeria }\end{array}$ & $\begin{array}{l}\text { Enterococcus faecium, } \\
\text { Staphylococcus aureus }\end{array}$ \\
\hline Daptomycin & Cyclic peptolide & $\begin{array}{l}\text { Ent. faecalis (vancomycin-susceptible), MSSA, } \\
\text { MRSA, Streptococcus agalactiae, Str. pyogenes }\end{array}$ & Staph. aureus, Ent. faecalis \\
\hline Quinupristin/dalfopristin & Streptogramin & $\begin{array}{l}\text { MSSA, group A, B, C, F, G, and viridans streptococci, } \\
\text { CoNS, MRSA, GRSA, GISA, VRE, VRSA, PRSP, } \\
\text { Propionibacterium acne, clostridia, lactobacilli }\end{array}$ & Ent. faecium, Staph. aureus \\
\hline Ertapenem & Carbapenem & $\begin{array}{l}\text { MSSA, Str. agalactiae, Str. pyogenes, } \\
\text { Enterobacter spp. }\end{array}$ & $\begin{array}{l}\text { MRSA, Str. agalactiae, } \\
\text { Str. pyogenes }\end{array}$ \\
\hline Moxifloxacin and gatifloxacin & Quinolone & $\begin{array}{l}\text { MSSA, CoNS, PRSP, group A, B, C, F, and G } \\
\text { streptococci }\end{array}$ & Staph. aureus \\
\hline Dalbavancin & Glycopeptide & $\begin{array}{l}\text { MSSA, MRSA, VRE, CoNS, most streptococci, } \\
\text { anaerobes }\end{array}$ & None to date \\
\hline
\end{tabular}


proven useful against SSSIs since its approval (Shah 2005), but has no useful activity against Gram-negative organisms (Strahilevitz \& Rubinstein 2002).

Newer quinolones, including levofloxacin, moxifloxacin, and gatifloxacin, have superior activity relative to ciprofloxacin against respiratory Gram-positive pathogens (Abbanat et al. 2003), but they do not cover MRSA, and may be compromised by crossresistance to older agents (Shah 2005). A number of novel cephalosporins are in development; these have shown promising activity against staphylococci but not against enterococci. However, some of these agents have shown good activity against Gram-negative pathogens such as Haemophilus influenzae and Moraxella catarrhalis. According to recent comment (Nathwani 2005), the novel carbapenem ertapenem was the last agent introduced that offered broad antimicrobial cover, but this drug is not active against methicillin- or oxacillin-resistant Gram-positive isolates and has limited activity against Pseudomonas species and ESBL-producing Gram-negative bacteria.

The novel streptogramin combination of quinupristin/dalfopristin has proven useful in patients with serious VRE infections and in SSSIs, including those with MRSA (Kauffman 2003; Raghavan \& Linden 2004). However, the combination is not active against infections caused by Ent. faecalis, and resistance has been reported (Chow et al. 1997; Dowzicky et al. 2000). Quinupristin/dalfopristin also has to be given via a central intravenous catheter to avoid phlebitis, and can cause painful arthralgia and myalgia (Kauffman 2003).

The glycopeptides vancomycin and teicoplanin (the latter is not available in the USA) have featured prominently in the management of multiresistant Gram-positive infection in the past, but around $20 \%$ of enterococci in the USA are now resistant to vancomycin (Abbanat et al. 2003). Moreover, vancomycin is ototoxic and nephrotoxic (BNF 2005). These considerations, and the threat of global acquisition of resistance to glycopeptides by MRSA, have led to the development of newer derivatives. These include ramoplanin, dalbavancin, and telavancin, all of which show promise and are in clinical development (Shah 2005; Bosso 2004).

There is therefore a need for research to discover and develop agents with activity against a range of both Gram-positive and Gram-negative pathogens, and against atypical pathogens, particularly those most frequently associated with institutional, resistant, or complicated infections. Moreover, research should be ongoing and aimed at the development of "pipelines" of new drugs, as resistance patterns are continually changing over time.

\section{Clinical evidence with tigecycline}

\section{Antimicrobial activity}

Tigecycline is active against most Gram-positive and Gramnegative aerobes in addition to anaerobes and atypical organisms. In preclinical studies, the drug was shown to have activity against a broad range of Gram-positive pathogens including MRSA, vancomycin-resistant Ent. faecalis and Ent. faecium, and penicillin-resistant Str. pneumoniae; against Gram-negative organisms such as ESBL-producing E. coli and Klebsiella pneumoniae; and anaerobes such as the Bacteroides fragilis group, and atypical organisms including Mycoplasma spp., Chlamydia spp., and rapidly growing mycobacteria (Edlund \& Nord 2000; Goldstein et al. 2000; Roblin \& Hammerschlag 2000; Kenny \& Cartwright 2001; Wallace et al. 2002; Jacobus et al. 2004). Tigecycline has also been shown in animal models to be active against a range of glycopeptide- and tetracycline-susceptible and -resistant enterococci (Lefort et al. 2003; Nannini et al. 2003), and the drug's antistaphylococcal activity has been confirmed against MRSA, being comparable to vancomycin and quinupristin/ dalfopristin, and superior to linezolid, imipenem, and beta-lactam antimicrobials (Johnson et al. 2003). Other recent data confirm antistaphylococcal activity against strains resistant to tetracycline, minocycline, erythromycin, clindamycin, gentamicin, levofloxacin, or rifampicin (Picazo et al. 2003), and against tetracycline- and minocycline-resistant bacteremia isolates (Reynolds \& Potz 2003).

The activity of tigecycline in clinical isolates was summarized on the basis of minimum inhibitory concentration (MIC) breakpoints of $\leq 2 \mathrm{mg} / \mathrm{L}$ and $\geq 8 \mathrm{mg} / \mathrm{L}$ for susceptibility and resistance, respectively (Garrison et al. 2005), but inconsistencies have been noted between MIC limits obtained in different studies during the establishment of quality control ranges for tigecycline. Because of this, further investigations have been carried out, and have identified discrepancies between results obtained in fresh Mueller-Hinton broth (MHB) and those in aged medium that have been attributed to acceleration of oxidative inactivation of tigecycline in the latter (Bradford et al. 2005a; Petersen \& Bradford 2005). As a result, the Clinical Laboratory Standards Institute has approved quality control ranges for tigecycline tested with fresh $\mathrm{MHB}$, and this is now considered the reference method for MIC testing of the drug (Clinical and Laboratory Standards Institute 2005).

These standards have been applied to in-vitro susceptibility testing of tigecycline with isolates from patients participating in phase III studies assessing the clinical efficacy of the drug in complicated SSSIs and intraabdominal infections (Bradford et al. 2005b). The results, which are summarized in Table 5, show a similar pattern to that seen in preclinical studies. Tigecycline was active (MIC $\leq 2 \mathrm{mg} / \mathrm{L}$ in most cases) against the most prevalent pathogens in these patients, which included both Gram-positive and Gram-negative strains of aerobic and anaerobic bacteria. Staphylococci were inhibited regardless of their susceptibility or otherwise to methicillin or oxacillin, and all enterococci were inhibited by tigecycline at a concentration of $0.5 \mathrm{mg} / \mathrm{L}$ or less. Good activity was also observed against beta-hemolytic streptococci, whereas MICs for $90 \%$ of isolates $\left(\mathrm{MIC}_{90}\right)$ for tetracycline and minocycline were above resistance breakpoints.

Activity against Gram-negative pathogens, particularly the Enterobacteriaceae, was also good (Table 5). All strains of Citrobacter freundii were inhibited (MIC $\leq 2 \mathrm{mg} / \mathrm{L}$ ), in contrast to minocycline, tetracycline, aztreonam, and ceftazidime, $\mathrm{MIC}_{90}$ values for all of which were above resistance breakpoints. All isolates of $E$. coli were inhibited by tigecycline at concentrations of 
Table 5 | In-vitro susceptibility data for tigecycline. Activity against isolates from phase III clinical studies in patients with skin and skin structure infections or intraabdominal infections (Bradford et el. 2005b)

Organism and no. of isolates (skin and skin structure

Skin and skin structure infections

Intraabdominal infections

infections; intraabdominal infections)

$\mathrm{MIC}_{50}(\mathrm{mg} / \mathrm{L})$

$\mathrm{MIC}_{90}(\mathrm{mg} / \mathrm{L})$

$\mathrm{MIC}_{50}(\mathrm{mg} / \mathrm{L})$

$\mathrm{MIC}_{90}(\mathrm{mg} / \mathrm{L})$

Gram-positive

Staphylococcus aureus: methicillin-resistant $(127 ; 16)$

Staphylococcus aureus: methicillin-susceptible $(373 ; 61)$

Staphylococcus capitis $(11 ; 7)$

Staphylococcus epidermidis: methicillin-resistant $(44 ; 30)$

Staphylococcus epidermidis: methicillin-susceptible $(36 ; 40)$

Staphylococcus haemolyticus $(26 ; 18)$

Staphylococcus hominis $(16 ; 19)$

Staphylococcus warneri $(10 ; 7)$

Enterococcus avium $(0 ; 57)$

Enterococcus faecalis: vancomycin-susceptible $(59 ; 109)$

Enterococcus faecium: vancomycin-susceptible $(11 ; 50)$

Enterococcus hirae $(3 ; 12)$

Streptococcus pyogenes $(84 ; 2)$

Streptococcus agalactiae $(32 ; 5)$

Streptococcus dysgalactiae $(14 ; 3)$

Streptococcus anginosus $(29 ; 154)$

Streptococcus constellatus $(2 ; 61)$

Streptococcus equisimilis $(11 ; 0)$

Streptococcus intemedius $(2 ; 10)$

Streptococcus mitis $(6 ; 16)$

Streptococcus oralis $(11 ; 37)$

Streptococcus salivarius (2; 20)

Gram-negative

Citrobacter braakii $(0 ; 15)$

Citrobacter freundii $(2 ; 29)$

Enterobacter cloacae $(41 ; 41)$

Escherichia coli $(90 ; 964)$

Klebsiella oxytoca $(18 ; 52)$

Klebsiella pneumoniae $(32 ; 152)$

Morganella morganii $(3 ; 19)$

Proteus mirabilis $(39 ; 46)$

Proteus vulgaris $(2 ; 10)$

Serratia marcescens $(10 ; 12)$

Acinetobacter calcoaceticus/baumanii complex $(16 ; 16)$

Pseudomona aeruginosa $(32 ; 126)$

Comamonas testosterone $(0 ; 10)$

Anaerobes

Bacteroides fragilis $(24 ; 244)$

Bacteroides caccae $(2 ; 19)$

Bacteroides distasonis $(0 ; 23)$

Bacteroides ovatus $(0 ; 21)$

Bacteroides thetaiomicron $(3 ; 108)$

Bacteroides uniformis $(4 ; 53)$

Bacteroides vulgatus $(0 ; 33)$

Clostridium innocuum $(1 ; 12)$

Clostridium perfringens $(5 ; 51)$

Eubacterium lentum $(0 ; 14)$

Propionibacterium acnes $(6 ; 17)$

Peptostreptococcus micros $(1 ; 39)$

Fusobacterium nucleatum $(4 ; 11)$

Veillonella spp. $(0 ; 12)$
0.12

0.12

0.12

0.12

0.12

0.25

0.12

0.12

NA

0.12

0.06

NA

0.06

0.06

0.12

0.06

NA

0.12

NA

NA

0.06

NA

NA

NA

0.5

0.25

0.25

0.5

NA

4

NA

1

0.25

16

NA

0.12

NA

NA

NA

NA

NA

NA

NA

NA

NA

NA

NA

NA

NA
0.25

0.25

0.25

0.5

0.25

1

0.12

0.25

NA

0.25

0.12

NA

0.12

0.25

0.25

0.12

NA

0.5

NA

NA

0.12

NA

NA

NA

1

0.5

0.5

1

NA

4

NA

2

1

32

NA

0.25

NA

NA

NA

NA

NA

NA

NA

NA

NA

NA

NA

NA

NA
0.25

0.12

NA

0.25

0.12

0.25

0.12

NA

0.12

0.12

0.06

0.06

NA

NA

NA

0.06

0.06

NA

0.06

0.06

0.06

0.06

0.5

0.5

1

0.25

0.5

0.5

2

2

1

2

0.5

16

0.06

0.5

0.25

2

0.25

0.5

0.25

0.25

$\leq 0.06$

0.12

0.12

$\leq 0.06$

$\leq 0.06$

0.12

0.25
0.25

0.25

NA

0.5

0.25

0.5

0.25

NA

0.12

0.25

0.12

0.06

NA

NA

NA

0.12

0.06

NA

0.12

0.12

0.12

0.12

0.5

1

1

0.5

0.5

1

2

4

2

4

2

32

0.12

4

8

2

4

2

1

2

$\leq 0.06$

1

0.5

0.12

$\leq 0.06$

0.12

0.5

$\mathrm{MIC}_{50}$, minimum inhibitory concentration for $50 \%$ of isolates; $\mathrm{MIC}_{90}$, minimum inhibitory concentration for $90 \%$ of isolates; NA, not applicable. 
$2 \mathrm{mg} / \mathrm{L}$ or less, and good activity was noted against $K$. pneumoniae isolates (including those that showed resistant to ceftazidime and aztreonam) and $K$. oxytoca. MICs ranged from 0.5 to $8 \mathrm{mg} / \mathrm{L}$ for Serratia marcescens, but lower values for most strains were reflected by the $\mathrm{MIC}_{50}$ values reported of 1 or $2 \mathrm{mg} / \mathrm{L}$. There was a trend towards higher MICs for the Proteeae than for other Enterobacteriaceae. For strains from patients with intraabdominal infections, $\mathrm{MIC}_{90}$ was $2 \mathrm{mg} / \mathrm{L}$ for Morganella morganii and Proteus vulgaris. Tigecycline was also active against Acinetobacter baumanii, but was less active against $P$ s. aeruginosa (Table 5).

Tigecycline was also active against anaerobic pathogens, and all Gram-positive anaerobes were inhibited by tigecycline $2 \mathrm{mg} / \mathrm{L}$ or less. There was a wide range of MICs against members of the $B$. fragilis group $(0.06-16 \mathrm{mg} / \mathrm{L})$, but $\mathrm{MIC}_{50}$ values for all species of Bacteroides were $2 \mathrm{mg} / \mathrm{L}$ or less.

\section{Clinical cure and microbiologic eradication in patients}

Clinical studies of tigecycline have focused to date on clinical cure and microbiologic eradication in patients with complicated SSSIs or intraabdominal infections. The primary endpoint of choice in such trials should be cure and eradication at a predefined test-of-cure visit that postdates the end of treatment. Cures that are apparent when treatment ceases may later relapse, with subsequent requirement for further therapy. Clinical evidence for the efficacy of tigecycline against the serious and complicated infection types examined to date appears good, and overall clinical activity is as might be expected on the basis of the drug's in-vitro bacteriologic profile.

In all studies reviewed, except for one phase II trial in which two dosages were compared, tigecycline was given intravenously as a
$100 \mathrm{mg}$ loading dose followed by $50 \mathrm{mg}$ every 12 hours for at least 5 days (Table 6 ). Two large, randomized, multicenter, double-blind phase III studies (level 2 evidence) have recently compared tigecycline with intravenous combination therapy with vancomycin $1 \mathrm{~g}$ and aztreonam $2 \mathrm{~g}$ every 12 hours for up to 14 days in 1057 patients [clinically modified intent-to-treat (ITT) populations] with complicated SSSIs (Breedt et al. 2005; Sacchidanand et al. 2005). Both studies showed no significant differences between either regimen in terms of clinical cure or microbiologic eradication rates (see also Table 6). Clinical cure rates (where treatment was observed to resolve the infection process) were measured in the clinically modified ITT populations (patients who received at least one dose of study drug and who showed clinical signs of a complicated SSSI) and microbiologic eradication in the microbiologically evaluable populations. Patients were deemed to be microbiologically evaluable if they satisfied all protocol requirements and had a baseline culture containing at least one causative isolate that was susceptible to both study treatments. Across the difference treatments in both studies, clinical cure rates ranged from 75.5 to $86.9 \%$ (Table 6).

Level 2 evidence is also available from two randomized, doubleblind, and multicenter studies comparing tigecycline with imipenem/cilastatin (500 mg/500 mg every 6 hours intravenously, weight-adjusted where necessary) for 5 to 14 days for complicated intraabdominal infections (Fomin et al. 2005; Oliva et al. 2005). Of 825 (Oliva et al. 2005) and 817 (Fomin et al. 2005) patients in the modified ITT populations who received more than one dose of study medication, 621 and 641, respectively, were included in the microbiologically modified ITT populations of patients who had clinical evidence of an intraabdominal infection, met minimal disease criteria, and who had a confirmed baseline isolate. Of these, 502 (Oliva et al. 2005) and 523 (Fomin et al.

Table 6 | Summary of outcomes evidence for tigecycline: clinical and microbiologic cure in patients with complicated skin and skin structure or intraabdominal infections

\begin{tabular}{|c|c|c|c|c|}
\hline $\begin{array}{l}\text { Level of } \\
\text { evidence }\end{array}$ & Outcomes & Comparators & Study population & Reference \\
\hline 2 & $\begin{array}{l}\text { CC in } 84.3 \% \text { (TIG) and } 86.9 \% \text { (VAN/AZT) of patients } \\
\text { (clinically modified ITT population). ME in } 84.8 \% \\
\text { and } 93.2 \% \text { for microbiologically evaluable population } \\
\text { of } 312 \text { (criteria for noninferiority of TIG met) }\end{array}$ & $\begin{array}{l}\text { TIG } 50 \mathrm{mg} \mathrm{q} 12 \mathrm{~h} \text { vs } \\
\text { VAN } 1 \mathrm{~g}+\text { AZT } 2 \mathrm{~g} \mathrm{q} 12 \mathrm{~h}\end{array}$ & $\begin{array}{l}\text { Clinically modified ITT population } \\
\text { of } 520 \text { with complicated skin and } \\
\text { skin structure infections }\end{array}$ & $\begin{array}{l}\text { Breedt et al. } \\
2005\end{array}$ \\
\hline 2 & $\begin{array}{l}\text { CC in } 75.5 \% \text { (TIG) and } 76.9 \% \text { (VAN/AZT) of patients } \\
\text { (clinically modified ITT population). ME in } 80.9 \% \\
\text { and } 77.9 \% \text { for microbiologically evaluable population } \\
\text { of } 228 \text { (criteria for noninferiority of TIG met) }\end{array}$ & $\begin{array}{l}\text { TIG } 50 \mathrm{mg} \mathrm{q} 12 \mathrm{~h} \text { vs } \\
\text { VAN } 1 \mathrm{~g}+\text { AZT } 2 \mathrm{~g} \mathrm{q} 12 \mathrm{~h}\end{array}$ & $\begin{array}{l}\text { Clinically modified ITT population } \\
\text { of } 537 \text { with complicated skin and } \\
\text { skin structure infections }\end{array}$ & $\begin{array}{l}\text { Sacchidanand } \\
\text { et al. } 2005\end{array}$ \\
\hline 2 & $\begin{array}{l}\text { CC in } 73.5 \% \text { (TIG) and } 78.2 \% \text { (IMI/CIL). ME in } 80.6 \% \\
\text { and } 82.4 \% \text { for microbiologically evaluable population } \\
\text { of } 502 \text { (criteria for noninferiority of TIG met) }\end{array}$ & $\begin{array}{l}\text { TIG } 50 \text { mg q } 12 \text { h vs IMI/CIL } \\
500 \text { mg/500 mg q } 6 \text { h }\end{array}$ & $\begin{array}{l}\text { Microbiologically modified ITT } \\
\text { population of } 621 \text { patients with } \\
\text { complicated intraabdominal infections }\end{array}$ & $\begin{array}{l}\text { Oliva et al. } \\
2005\end{array}$ \\
\hline 2 & $\begin{array}{l}\text { CC in } 86.6 \% \text { (TIG) and } 84.6 \% \text { (IMI/CIL). ME in } 91.3 \% \\
\text { and } 89.9 \% \text { for microbiologically evaluable population } \\
\text { of } 523 \text { (criteria for noninferiority of TIG met) }\end{array}$ & $\begin{array}{l}\text { TIG } 50 \text { mg q } 12 \text { h vs IMI/CIL } \\
500 \text { mg/500 mg q } 6 \text { h }\end{array}$ & $\begin{array}{l}\text { Microbiologically modified ITT } \\
\text { population of } 641 \text { patients with } \\
\text { complicated intraabdominal infections }\end{array}$ & $\begin{array}{l}\text { Fomin et al. } \\
2005\end{array}$ \\
\hline 3 & $\begin{array}{l}\text { CC in } 67 \% \text { (TIG } 25 \mathrm{mg} \text { ) and } 74 \% \text { (TIG } 50 \mathrm{mg} \text { ) of } \\
\text { patients. ME in } 56 \% \text { and } 69 \%\end{array}$ & $\begin{array}{l}\text { TIG } 25 \mathrm{mg} \mathrm{q} 12 \mathrm{~h} \text { vs } \\
\text { TIG } 50 \mathrm{mg} \mathrm{q} 12 \mathrm{~h}\end{array}$ & $\begin{array}{l}160 \text { with complicated skin and } \\
\text { skin structure infections }\end{array}$ & $\begin{array}{l}\text { Postier et al. } \\
2004\end{array}$ \\
\hline 3 & CC in $55 \%$ of patients & TIG 50 mg q 12 h & $\begin{array}{l}111 \text { with complicated intraabdominal } \\
\text { infections }\end{array}$ & $\begin{array}{l}\text { Murray et al. } \\
2003\end{array}$ \\
\hline 5 & $\begin{array}{l}\text { Full recovery with TIG }(n=2) \text {; no response with } \\
\text { colistin }(n=5)\end{array}$ & TIG (dosage not stated) & $\begin{array}{l}7 \text { ventilator-assisted patients with resistant } \\
\text { Acinetobacter baumanii pneumonia }\end{array}$ & Wilson 2004 \\
\hline
\end{tabular}


2005) were microbiologically evaluable. The mean duration of therapy across both studies was approximately 8 days. At the test-of-cure assessment (12-44 days after therapy), clinical cure rates were 73.5 (Oliva et al. 2005) and 86.6\% (Fomin et al. 2005) for tigecycline, and 78.2 (Oliva et al. 2005) and 84.6\% (Fomin et al. 2005) for imipenem/cilastatin (Table 6). At approximately 80 (Oliva et al. 2005) and $90 \%$ (Fomin et al. 2005), rates of microbiologic eradication were also similar between treatments in both studies for microbiologically evaluable populations. Tigecycline met statistical criteria for noninferiority to imipenem/cilastatin for all endpoints in both studies.

The most common diagnosis in both studies was complicated appendicitis (around half of all patients overall), followed by perforated intestine and gastric or duodenal ulcer (Oliva et al. 2005), or by cholecystitis or intraabdominal abscess (Fomin et al. 2005). E. coli was the most commonly isolated aerobe, followed by Klebsiella spp., in both trials. Oliva et al. (2005) reported identification of six ESBL-producing $E$. coli and seven ESBLproducing $K$. pneumoniae isolates before therapy in their study.

Postier et al. (2004) have reported fully their phase II study (level 3 evidence) in 160 ITT patients with complicated SSSIs who received tigecycline $25 \mathrm{mg}(\mathrm{n}=79)$ or $50 \mathrm{mg}(\mathrm{n}=81)$ every 12 hours for 7-14 days. The primary endpoint in this well-designed and executed study was clinically observed cure (defined as resolution or improvement of all signs and symptoms to the extent that no further antibiotic therapy was necessary) at the test-ofcure visit approximately 3 weeks after the start of therapy. Bacteriologic responses were assessed according to the National Committee for Clinical Laboratory Standards (NCCLS; now known as the Clinical Laboratory Standards Institute) criteria and clearly defined MIC breakpoints; pharmacokinetic and safety analyses were also included. The main diagnoses were ulcer with acute infection (35\% of patients) and major abscess (31\%). Of all patients, $82 \%$ were infected with at least one of the pathogens selected for bacteriologic analysis: methicillin-resistant or -sensitive Staph. aureus, Str. pyogenes, E. coli, Ent. faecalis, or Ent. faecium. As shown in Table 6, clinical cure as specified was noted in 67 and $74 \%$ of patients in the $25 \mathrm{mg}$ and $50 \mathrm{mg}$ groups, respectively, at the test-of-cure visit (six patients in each group required further treatment between the end-of-treatment and testof-cure visits). In the $25 \mathrm{mg}$ group, $56 \%$ of patients had microbiologic eradication, which was compared with $69 \%$ in the $50 \mathrm{mg}$ group. The MICs required for $90 \%$ of all selected isolates ranged from 0.06 to $0.5 \mathrm{mg} / \mathrm{L}$ (Postier et al. 2004).

Tigecycline was also effective in patients with complicated intraabdominal infections (mostly perforated or gangrenous appendicitis, complicated cholecystitis, perforated diverticulitis, or peritonitis) in a noncomparative phase II study (Murray et al. 2003). In this trial, presented as an abstract and summarized in Table 6, 111 ITT patients received tigecycline for up to 14 days, after which $55 \%$ were assessed as clinically cured at the test-ofcure visit. These patients represented a challenging population, meeting inclusion criteria that included a need for surgical extirpation of the source of infection plus antibiotic therapy, and subsequent isolation of both aerobic and anaerobic cultures.
Although not considered strong evidence, a small descriptive study (level 5 evidence) in a series of seven patients requiring intensive care in a UK district general hospital has indicated that tigecycline is likely to be useful in persons with ventilatorassisted pneumonia associated with resistant Acinetobacter infection (Table 6) (Wilson 2004). Tigecycline was tried successfully in two patients in this unit after increasing problems with resistance to carbapenems, tobramycin, amikacin, colistin, and minocycline, to the point where one patient had already died with $A$. baumanii infection resistant to all available antiinfective agents. The other five patients in this series were treated with colistin and failed to respond, but it was not clear from the abstract presented as to how these patients were managed thereafter.

\section{Tolerability and adverse events}

Clinical results to date bear out preclinical findings with tigecycline in healthy persons and those with renal disease that showed linear pharmacokinetics and good tolerability of the drug with no need for dosage adjustments because of age, gender, or renal impairment (Troy et al. 2003; Meagher et al. 2004; Muralidharan et al. 2005a,b). Nausea and vomiting appear to be the treatment-emergent adverse events of chief concern, and affected $35 \%$ of patients who received tigecycline 50 mg every 12 hours in the phase II study of Postier et al. (2004). Of the five treatment withdrawals, two were associated with nausea and vomiting and one with rash; none of these events were life threatening. Laboratory abnormalities (elevated hepatic enzymes, raised blood urea nitrogen levels, or anemia) considered likely to be associated with tigecycline therapy were also noted in nine patients, but none led to treatment discontinuation. Overall, nausea and vomiting were cited as the most common events with tigecycline in all other studies. Rates were higher than with vancomycin/aztreonam in patients with complicated SSSIs in phase III trials (Breedt et al. 2005; Sacchadinand et al. 2005), although vancomycin/aztreonam was associated with higher rates of hepatic enzyme elevation, pruritus, and rash (Table 7). In one phase III study in patients with intraabdominal infections, the increases in rates of nausea and vomiting with tigecycline over imipenem/cilastatin approached or attained statistical significance (Table 7), but there were no statistically significant differences between groups in this respect in the other phase III intraabdominal infection trial (Fomin et al. 2005).

\section{Ongoing studies}

The studies reported so far indicate the likely utility of tigecycline in complicated and/or nosocomial infections of particular interest at the present time, but trials are also in progress to examine the activity of the drug in other serious and problematic infections. These include:

- an open-label and noncomparative trial in patients with serious resistant Gram-negative infections (e.g. A. baumanii, Enterobacter spp., K. pneumoniae, etc.) (evidence level 3)

- randomized and double-blind comparisons with levofloxacin in patients with community-acquired pneumonia (evidence level 2) 
Table 7 | Summary of outcomes evidence for tigecycline: adverse events

\begin{tabular}{|c|c|c|c|c|}
\hline $\begin{array}{l}\text { Level of } \\
\text { evidence }\end{array}$ & Outcomes & Comparators & Study population & Reference \\
\hline 2 & $\begin{array}{l}\text { Similar rates of TEAEs in both groups. More }(P<0.05) \\
\text { nausea }(25.2 \text { vs } 5.2 \%) \text { and vomiting }(12 \text { vs } 2.2 \%) \\
\text { with TIG; more increased AST ( } 5.2 \text { vs } 1.5 \%) \text { or ALT } \\
(6.7 \text { vs } 1.8 \%) \text { with VAN/AZT }\end{array}$ & $\begin{array}{l}\text { TIG } 50 \mathrm{mg} \mathrm{q} 12 \mathrm{~h} \text { vs VAN } \\
1 \mathrm{~g}+\mathrm{AZT} 2 \mathrm{~g} \mathrm{q} 12 \mathrm{~h}\end{array}$ & $\begin{array}{l}\text { Safety population of } 543 \text { with complicated } \\
\text { skin and skin structure infections }\end{array}$ & $\begin{array}{l}\text { Breedt et al. } \\
2005\end{array}$ \\
\hline 2 & $\begin{array}{l}\text { Similar rates of TEAEs in both groups. More }(P<0.05) \\
\text { nausea }(43.2 \text { vs } 11 \%) \text {, vomiting }(26.7 \text { vs } 5 \%) \text {, } \\
\text { dyspepsia ( } 5.5 \text { vs } 1.8 \%) \text {, and anorexia }(4.1 \text { vs } 0.7 \%) \\
\text { with TIG; more abnormal LFTs }(5.7 \text { vs } 1 \%) \text {, pruritus } \\
\text { (10.7 vs } 4.5 \%) \text {, and rash ( } 7.8 \text { vs } 2.7 \%) \text { with VAN/AZT }\end{array}$ & $\begin{array}{l}\text { TIG } 50 \mathrm{mg} \mathrm{q} 12 \mathrm{~h} \text { vs VAN } \\
1 \mathrm{~g}+\mathrm{AZT} 2 \mathrm{~g} \mathrm{q} 12 \mathrm{~h}\end{array}$ & $\begin{array}{l}\text { Safety population of } 573 \text { patients with } \\
\text { complicated skin and skin structure } \\
\text { infections }\end{array}$ & $\begin{array}{l}\text { Sacchadinand } \\
\text { et al. } 2005\end{array}$ \\
\hline 2 & $\begin{array}{l}\text { Most common TEAEs: nausea ( } 31 \% \text { TIG and } 24.8 \% \\
\text { IMI/CIL; } P=0.052) \text { and vomiting ( } 25.7 \% \text { TIG and } 19.4 \% \\
\text { IMI/CIL; } P=0.037)\end{array}$ & $\begin{array}{l}\text { TIG } 50 \mathrm{mg} \mathrm{q} 12 \mathrm{~h} \mathrm{vs} \mathrm{IMI/ClL} \\
500 \mathrm{mg} / 500 \mathrm{mg} \mathrm{q} 6 \mathrm{~h}\end{array}$ & $\begin{array}{l}\text { Modified ITT cohort of } 825 \text { patients with } \\
\text { complicated intraabdominal infections }\end{array}$ & $\begin{array}{l}\text { Oliva et al. } \\
2005\end{array}$ \\
\hline 2 & $\begin{array}{l}\text { Most common TEAEs: nausea ( } 17.6 \% \mathrm{TIG} \text { and } 13.3 \% \\
\text { IMI/CIL; } P=0.1) \text { and vomiting }(12.6 \% \mathrm{TIG} \text { and } \\
9.2 \% \text { IMI/CIL; } P=0.144)\end{array}$ & $\begin{array}{l}\text { TIG } 50 \mathrm{mg} \mathrm{q} 12 \mathrm{~h} \mathrm{vs} \mathrm{IMI/ClL} \\
500 \mathrm{mg} / 500 \mathrm{mg} \mathrm{q} 6 \mathrm{~h}\end{array}$ & $\begin{array}{l}\text { Modified ITT cohort of } 817 \text { patients with } \\
\text { complicated intraabdominal infections }\end{array}$ & $\begin{array}{l}\text { Fomin et al. } \\
2005\end{array}$ \\
\hline 3 & $\begin{array}{l}\text { Commonest TEAEs: nausea ( } 22 \% \text { with } 25 \mathrm{mg} ; 35 \% \\
\text { with } 50 \mathrm{mg} \text { ). } 5 \text { discontinuations with } 50 \mathrm{mg} \text {. } \\
\text { No life-threatening reactions }\end{array}$ & $\begin{array}{l}\text { TIG } 25 \mathrm{mg} \mathrm{q} 12 \mathrm{~h} \text { vs TIG } \\
50 \mathrm{mg} \mathrm{q} 12 \mathrm{~h}\end{array}$ & $\begin{array}{l}160 \text { with complicated skin and skin } \\
\text { structure infections }\end{array}$ & $\begin{array}{l}\text { Postier et al. } \\
2004\end{array}$ \\
\hline 5 & No adverse events with TIG therapy & TIG (dosage not stated) & $\begin{array}{l}7 \text { ventilator-assisted patients with resistant } \\
\text { Acinetobacter baumanii pneumonia; } 2 \text { received } \\
\text { TIG, } 5 \text { received colistin }\end{array}$ & Wilson 2004 \\
\hline
\end{tabular}

- a randomized and double-blind comparison with linezolid for serious infections in patients with VRE, and with vancomycin for serious infections in patients with MRSA. Conditions covered include bacteremia, pneumonia, and bacterial SSSIs (evidence level 2)

- a randomized and double-blind comparison with imipenem/ cilastatin in patients with nosocomial pneumonia (evidence level 2).

Completion of these large-scale studies will provide a more complete picture of the overall activity of tigecycline in patients with infections associated with major management problems at the present time, and results are therefore awaited.

\section{Economic evidence}

Early level 3 evidence, presented as an abstract, suggests that reduction of length of hospital stay may accrue from the use of tigecycline in patients with complicated SSSIs (Table 8). Pooling of data from two randomized, double-blind, international studies (Breedt et al. 2005; Sacchidanand et al. 2005) in a modified ITT population of 1116 patients with complicated SSSIs showed no difference in length of hospital stay between patients receiving tigecycline and those receiving vancomycin/aztreonam (Mallick \& Solomon 2005). However, when risk factors for significantly longer stay (diabetes, trauma, Gram-negative infection, absence of cure, use of concomitant medication, infected ulcer, need for intensive care, and non-US hospital setting) were identified and adjusted for, tigecycline therapy was associated with a significant 1-day reduction in length of hospital stay. This difference was almost entirely attributable to the subgroup of patients with
Gram-negative infections (18\%, mostly E. coli). Among 186 clinical intent-to-treat patients treated in US centers and with complete hospitalization data (Mallick et al. 2005), tigecycline was associated with a reduction in length of hospital stay of 1.6 days $(P=0.04)$ after adjusting for identified risk factors that included prior surgery (+2.9 days; $P=0.036)$ and initiation of intravenous antibiotic treatment in the intensive care unit (+10.8 days; $P=0.0008$ ).

Yu et al. (2005) have reported a nonsignificant trend towards reduced duration of treatment relative to vancomycin/aztreonam when patients with complicated SSSIs were treated with tigecycline (Table 8). This analysis was based retrospectively on the same two clinical studies as above (Breedt et al. 2005; Sacchidanand et al. 2005), and included 1041 patients from the modified ITT population with complete hospitalization data. Independent risk factors for prolonged hospitalization that were identified and adjusted for were diabetes, infected ulcer, female gender, and concomitant use of antibiotics. It should be noted here that length of stay and duration of treatment were only two of several measured health outcomes, and that their reduction were not prospectively defined in the protocols of the two clinical trials on which these economic analyses were based.

\section{Resource utilization}

Apart from the preliminary level 3 evidence described in the previous section, there are as yet no other published economic data relating to the use of tigecycline at this stage in the drug's development, but results indicate the potential of novel antiinfectives such as tigecycline in complicated, nosocomial, and/or resistant infections. The pace at which resistance to 
Table 8 | Summary of economic outcomes for tigecycline

\begin{tabular}{|c|c|c|c|c|}
\hline $\begin{array}{l}\text { Level of } \\
\text { evidence }\end{array}$ & Outcomes & Comparators & Study population & Reference \\
\hline 2 & $\begin{array}{l}\text { Trend towards shorter treatment duration }(P=0.072) \\
\text { with TIG after adjustment for risk factors }\end{array}$ & $\begin{array}{l}\text { TIG } 50 \mathrm{mg} \mathrm{q} 12 \mathrm{~h} \text { vs VAN } \\
1 \mathrm{~g}+\text { AZT } 2 \mathrm{~g} \mathrm{q} 12 \mathrm{~h}\end{array}$ & $\begin{array}{l}1041 \text { with complicated skin and skin } \\
\text { structure infections and with complete } \\
\text { hospitalization data }\end{array}$ & Yu et al. 2005 \\
\hline 3 & $\begin{array}{l}\text { Faster discharge }(-1 \text { day; hazard ratio } 1.22 ; P=0.019) \\
\text { with TIG after adjustment for risk factors. Discharge } \\
\text { time reduced by } 1.6 \text { days }(P=0.04) \text { when restricted to } \\
186 \text { patients from US centers and with complete data }\end{array}$ & $\begin{array}{l}\text { TIG } 50 \mathrm{mg} \mathrm{q} 12 \mathrm{~h} \text { vs VAN } \\
1 \mathrm{~g}+\text { AZT } 2 \mathrm{~g} \mathrm{q} 12 \mathrm{~h}\end{array}$ & $\begin{array}{l}1116 \text { with complicated skin and skin } \\
\text { structure infections }\end{array}$ & $\begin{array}{l}\text { Mallick \& } \\
\text { Solomon 2005; } \\
\text { Mallick et al. } \\
2005\end{array}$ \\
\hline
\end{tabular}

antimicrobial therapy develops continues to increase, but the magnitude of the effect of this resistance on outcomes and consumption of healthcare resources remains poorly understood. A review of this subject by Cosgrove and Carmeli (2003) has attempted to address these issues. Resistance often leads to a mismatch between empiric treatment and susceptibility, and thus to a significant delay in the delivery of effective antimicrobial therapy. Such delay resulted in significantly extended duration of hospitalization and increased hospital charges for patients with ESBL-producing strains of $K$. pneumoniae or $E$. coli relative to controls in one study (Lautenbach et al. 2001). Resistant organisms may also require treatment with more toxic or aggressive therapy than might usually be considered: colistin for resistant Pseudomonas or Acinetobacter strains may cause renal dysfunction (Levine et al. 1991), and total resistance may lead to the need for surgery, with high rates of mortality being seen in patients whose locus of infection cannot be surgically removed (Harris et al. 1999).

From the hospital perspective, most available studies have shown a link between antibiotic resistance and increased mortality, morbidity, and cost (Cosgrove \& Carmeli 2003). These results, however, are limited because they do not include costs associated with care in the community and in rehabilitation facilities other than hospitals. The long-term effects of a resistant infection on future health, and on loss of work and family time caused by prolonged hospitalization or incapacity, are also difficult to estimate. The US Congress Office of Technology Assessment (1995) estimated the national cost of antibiotic resistance in that country to be \$US4 billion for the year 1995, but this conservative assessment included only direct patient effects without wider societal costs.

The chief value of antiinfective drugs introduced at the present time for the types of infection under discussion lies in their potential in empiric therapy. Any agent that can be given with a good chance of success early in the course of disease will contribute to the avoidance of much morbidity and need for additional therapy following on from treatment failure as described above. Clinical results show that tigecycline is likely to fall into this category, but reliable outcomes and economic data pertaining to the use of the drug will have to be assessed in direct comparisons with other therapies in specified institutions, as treatment and resistance patterns vary between locations within and between countries. The cost to providers of drugs used in any study will also have to be known for reliable comparisons to be made, as acquisition costs for novel broad-spectrum antibiotics are typically much higher than those of established agents. Nevertheless, the activity of tigecycline in preclinical and clinical studies to date suggest that the drug does indeed have the potential to circumvent adverse outcomes and subsequent costs resulting from treatment failure in complicated and resistant infections.

\section{Patient group/population}

Current product registration in the USA limits the use of tigecycline to adults with intraabdominal and complicated SSSIs, but the range of clinical trials still underway indicates that the drug is expected to contribute to the treatment of patients with a much wider range of conditions caused by multiresistant pathogens. Chief among these are likely to be patients with pneumonia (both hospital- and community-acquired), including some with atypical infections, patients with bacteremia/sepsis, and those with Gramnegative infections. Patients in the last group may benefit in particular, as tigecycline has good activity against a number of Gram-negative pathogens that are resistant to other novel antibacterials, most of which are directed against Gram-positive infections (Abbanat et al. 2003; Nathwani 2005). There is no oral formulation of tigecycline, and the drug must be given intravenously, but this consideration is of little consequence in light of the characteristics of the target patient group, the large majority of whom will have undergone surgery or will be sufficiently unwell to require care in hospital or some other institutional setting.

Preliminary level 5 evidence indicates that tigecycline is also likely to be useful in high-risk patients in intensive care who are particularly vulnerable to multiresistant pathogens (Wilson 2004). Ethical considerations make the conduct of randomized trials in patients of this type more difficult than in other groups, but accumulating clinical experience with tigecycline is likely to shed more light on the utility of the drug in this setting.

The use of tigecycline is likely to be empiric in the first instance in many patients, as early treatment is important in the management of serious infections. The broad spectrum of activity, which includes Gram-negative pathogens and some atypical organisms, suggests that this empiric therapy will be continued and should be successful in most patients after identification of the infective 
agent. This situation could change, however, if resistance were to emerge, and it will therefore be important to combine appropriate use of tigecycline with effective infection control measures and close monitoring of susceptibility patterns.

Tigecycline has been approved in the USA, Mexico, Venezuela, and Brazil for the treatment of complicated intraabdominal infections and complicated skin and skin structure infections in adults (Anon. 2005). It is likely that these indications will be expanded as the results of ongoing phase III studies are released (filings are expected for hospital- and community-acquired pneumonia in September 2006). Registration is awaited in Australia, Canada, the European Union, and Switzerland. The use of tigecycline in children has not yet been evaluated.

\section{Outcomes summary}

Tigecycline has recently been introduced into clinical practice as part of the effort to combat the growing problem of bacterial resistance to antiinfective therapy, particularly in patients with serious or complicated infections and those in hospitals and other institutions. Early reports of the first of the large-scale randomized clinical trials to be conducted have led to the approval of tigecycline for the treatment of complicated SSSIs and intraabdominal infections in the USA, Mexico, Venezuela, and Brazil, with approvals expected to follow in other countries, and other indications added, as ongoing studies report. Published or impending trials focus on comparisons of tigecycline with established agents that are already in common use for serious infections. Substantial evidence so far shows that tigecycline is as effective as these other agents, but superiority has not been shown. As resistance patterns vary widely between centers and countries, more research and clinical experience will be necessary before a more complete picture begins to emerge. Comparisons of tigecycline with other new agents developed specifically for use against the modern generation of multiresistant pathogens will also be needed. These will be of special interest because of tigecycline's activity against Gram-negative and some atypical pathogens.

The possibility of development of resistance to any new antimicrobial is a significant source of concern. Tigecycline appears to have the potential to resist common mechanisms of resistance, as shown by unsuccessful attempts to create tigecycline-resistant isolates in the laboratory by exposing pathogens to suboptimal concentrations of the drug (Projan 2000). In addition, tigecycline is not affected by efflux, ribosomal protection, DNA gyrase mutation, binding site modification, or beta-lactamases (Bradford 2004).

Clinical endpoints being measured in trials are as expected for a new antiinfective agent. The outcomes of clinical cure and bacteriologic eradication have immediate clinical relevance and show how well the drug works in the setting in which it is given. However, the economic implications attached to the introduction of tigecycline to clinical practice are less clear at present. For economic benefits to be realized, tigecycline will have to maintain high rates of clinical success against organisms resistant to other drugs, with sustained efficacy as empiric therapy in cases where other agents may fail. Longer term evaluation will be needed to show how these factors translate into other (e.g. quality-of-life and societal) benefits beyond the perspective of the institution where treatment is administered. Limited evidence suggests that the use of tigecycline may result in more rapid discharge of patients from hospital back into the community; ultimately, this will require confirmation with evidence from properly designed economic studies. It would also be of value to determine any effect of tigecycline on length of stay in intensive care. Tolerability in clinical studies appears good, and similar to the beta-lactam comparators used to date (imipenem/cilastatin and aztreonam are associated chiefly with nausea, vomiting, and diarrhea). Vancomycin may be ototoxic and hepatotoxic in some patients, but tigecycline does not appear to be associated with potentially serious effects such as organ toxicity.

The introduction of tigecycline is timely in an era of increasing bacterial resistance and relative shortage of new antibacterial agents. Current evidence shows that this novel glycylcycline is effective in the patient population in which it is being targeted, but it is not yet clear whether it is more effective or delivers better outcomes than other agents of interest. Continuing evolution of resistance patterns worldwide will no doubt affect the relative placing of tigecycline and other antiinfectives (both old and new), and further evidence will need to be gathered to show whether overall benefits outweigh high acquisition costs (as with all novel antibacterials) relative to older agents.

\section{References}

Abbanat D, Macielag M, Bush K. Novel antibacterial agents for the treatment of serious Gram-positive infections. Expert Opin Investig Drugs. 2003;12:379-399.

Anon. Recommendations for preventing the spread of vancomycin resistance: recommendations of the Hospital Infection Control Practices Advisory Committee (HICPAC). Am J Infect Control. 1995;23:87-94.

Anon. Monitoring hospital-acquired infections to promote patient safety United States, 1990-1999. MMWR Morb Mortal Wkly Rep. 2000;49:149-153.

Anon. FDA approves superbug antibiotic, Tygacil (tigecycline). Medical News Today. June 17, 2005. Available at: http://www.medicalnewstoday.com/ medicalnews.php?newsid=26293\# (accessed June 24, 2005).

BNF (British National Formulary) 49; March, 2005. Available at: http://www.bnf.org/bnf (accessed July 6, 2005).

Bosso JA. The impact of antibiotic management on resistance. Pharmacotherapy. 2004;24:224S-231S.

Bradford PA. Tigecycline: a novel first in class glycylcycline. Clin Microbiol Newslett. 2004;26:163-168.

Bradford PA, Petersen PJ, Young M, Jones CH, Tischler M, O'Connell J. Tigecycline MIC testing by broth dilution requires use of fresh medium or addition of the biocatalytic oxygen-reducing agent oxyrase to standardize the test method. Antimicrob Agents Chemother. 2005a;49:3903-3909.

Bradford PA, Weaver-Sands T, Petersen PJ. In vitro activity of tigecycline against isolates from patients enrolled in phase 3 clinical trials of treatment for complicated skin and skin-structure infections and complicated intra-abdominal infections. Clin Infect Dis. 2005b;41:S315-S332.

Breedt J, Teras J, Gardovskis J, et al. Safety and efficacy of tigecycline in treatment of skin and skin structure infections: results of a double-blind phase 3 comparison study with vancomycin-aztreonam. Antimicrob Agents Chemother. 2005;49:4658-4666.

Chopra I. Glycylcyclines: third-generation tetracycline antibiotics. Curr Opin Pharmacol. 2001;1:464-469. 
Chow JW, Donahedian SM, Zervos MJ. Emergence of increased resistance to quinupristin/dalfopristin during therapy for Enterococcus faecium bacteremia. Clin Infect Dis. 1997;24:90-91.

Clinical and Laboratory Standards Institute. Performance standards for antimicrobial susceptibility testing - fifteenth informational supplement. Wayne, PA: Clinical and Laboratory Standards Institute; 2005. CLSI document number M100-S15.

Cosgrove SE, Carmeli Y. The impact of antimicrobial resistance on health and economic outcomes. Clin Infect Dis. 2003;36:1433-1437.

Crowcroft NS, Catchpole M. Mortality from methicillin-resistant Staphylococcus aureus in England and Wales: analysis of death certificates. BMJ. 2002;325:1390-1391.

Diekema DJ, BootsMiller BJ, Vaughn TE, et al. Antimicrobial resistance trends and outbreak frequency in United States hospitals. Clin Infect Dis. 2004;38:78-85.

Dowzicky M, Talbot GH, Feger C, Prokocimer P, Etienne J, Leclerq R. Characterization of isolates associated with emerging resistance to quinupristin/dalfopristin (Synercid) during a worldwide clinical program. Diagn Microbiol Infect Dis. 2000;37:57-62.

Edlund C, Nord CE. In-vitro susceptibility of anaerobic bacteria to GAR-936, a new glycylcycline. Clin Microbiol Infect. 2000;6:159-163.

Fomin P, Beuran M, Gradauskas A, et al; 306 Study Group. Tigecycline is efficacious in the treatment of complicated intra-abdominal infections. Int $J$ Surg. 2005;3:35-47.

Garrison MW, Neumiller JJ, Setter SM. Tigecycline: an investigational glycylcycline antimicrobial with activity against resistant Gram-positive organisms. Clin Ther. 2005;27:12-22.

Goldstein EJC, Citron DM, Merriam CV, Warren Y, Tyrrell K. Comparative in vitro activities of GAR-396 against aerobic and anaerobic animal and human bite wound pathogens. Antimicrob Agents Chemother. 2000;44:2747-2751.

Gravestock MB. Recent developments in the discovery of novel oxazolidinone antibacterials. Curr Opin Drug Discov Devel. 2005;8:469-477.

Guay DR. Oritavancin and tigecycline: investigational antimicrobials for multidrug-resistant bacteria. Pharmacotherapy. 2004;24:58-68.

Halle E, Padberg J, Rosseau S, Klare I, Werner G, Witte W. Linezolid-resistant Enterococcus faecium and Enterococcus faecalis isolated from a septic patient: report of first isolates in Germany. Infection. 2004;32:182-183.

Harris A, Torres-Viera C, Venkataraman L, DeGirolami P, Samore M, Carmeli Y. Epidemiology and clinical outcomes of patients with multiresistant Pseudomonas aeruginosa. Clin Infect Dis. 1999;28:1128-1133.

IDSA (Infectious Diseases Society of America). Bad bugs, no drugs. As antibiotic discovery stagnates... a public health crisis brews. Available at: http://www.idsociety.org/ (accessed June 24, 2005a).

IDSA (Infectious Diseases Society of America). Bad bugs, no drugs executive summary. Antibiotic-resistant bacterial pathogens: why we are concerned? Available at: http://www.idsociety.org/ (accessed June 24, 2005b).

Jacobus NV, McDermott LA, Ruthazer R, Snydman DR. In vitro activities of tigecycline against the Bacteroides fragilis group. Antimicrob Agents Chemother. 2004;48:1034-1036.

Johnson B, Stevens T, Bouchillon S, et al. Tigecycline (GAR-936) a novel glycylcycline with promising anti-staphylococcal activity. Proceedings of the 43rd Annual Interscience Conference on Antimicrobial Agents and Chemotherapy; September 14-17, 2003; Chicago, IL. Abstract E-1536.

Kauffman CA. Therapeutic and preventative options for the management of vancomycin-resistant enterococcal infections. J Antimicrob Chemother. 2003;51(Suppl. S3):iii23-iii30.

Kenny GE, Cartwright FD. Susceptibilities of Mycoplasma hominis, M. pneumoniae, and Ureaplasma urealyticum to GAR-396, dalfopristin, dirithromycin, evernimicin, gatifloxacin, linezolid, moxifloxacin, quinupristindalfopristin, and telithromycin compared to their susceptibilities to reference macrolides, tetracyclines, and quinolones. Antimicrob Agents Chemother. 2001;45:2604-2608.

Lautenbach E, Patel JB, Bilker WB, Edelstein PH, Fishman NO. Extendedspectrum beta-lactamase-producing Escherichia coli and Klebsiella pneumoniae: risk factors for infection and impact of resistance on outcomes. Clin Infect Dis. 2001;32:1162-1171.
Lefort A, Lafaurie M, Massias L, et al. Activity and diffusion of tigecycline (GAR936) in experimental enterococcal endocarditis. Antimicrob Agents Chemother. 2003;47:216-222.

Levine DP, Fromm BS, Reddy BR. Slow response to vancomycin or vancomycin plus rifampicin in methicillin-resistant Staphylococcus aureus endocarditis. Ann Intern Med. 1991;115:674-680.

Mallick R, Solomon S. The duration of hospitalization (length of stay) in patients hospitalized with complicated skin and skin structure infections: identifying clinical and microbiological risk factors in a comparison of tigecycline with vancomycin/aztreonam. 15th European Congress of Clinical Microbiology and Infectious Diseases; May 1-4, 2005; Prague, Czech Republic. Abstract P1181.

Mallick R, Yu H, Weber DJ. Length of stay in patients hospitalized in the United States with complicated skin and skin structure infections (cSSSI): Findings from pooled clinical studies comparing tigecycline and vancomycin/aztreonam. Infectious Disease Society of America, 43rd Annual Meeting; October 6-9, 2005; San Francisco, CA. Abstract 367.

Mangili A, Bica I, Snydman DR, Hamer DH. Daptomycin-resistant, methicillinresistant Staphylococcus aureus bacteremia. Clin Infect Dis. 2005;40:1058-1060.

Meagher A, Cirincione B, Piedmonte M, Troy S, Ambrose PG. Pharmacokinetics of tigecycline in healthy adult volunteers and in subjects with renal impairment. 14th European Congress of Clinical Microbiology and Infectious Diseases; May 1-4, 2004; Prague, Czech Republic. Abstract P1023.

Meka VG, Pillai SK, Sakoulas G, et al. Linezolid resistance in sequential Staphylococcus aureus isolates associated with a T2500A mutation in the 23S rRNA gene and loss of a single copy of rRNA. $J$ Infect Dis. 2004;190:311-317.

Muralidharan G, Fruncillo RJ, Micalizzi M, Raible DG, Troy SM. Effects of age and sex on single-dose pharmacokinetics of tigecycline in healthy subjects. Antimicrob Agents Chemother. 2005a;49:1656-1659.

Muralidharan G, Micalizzi M, Speth J, Raible D, Troy S. Pharmacokinetics of tigecycline after single and multiple doses in healthy subjects. Antimicrob Agents Chemother. 2005b;49:220-229.

Murray J, Wilson S, Klein S, Yellin A, Loh E. The clinical response to tigecycline in the treatment of complicated intra-abdominal infections in hospitalized patients, a phase 2 clinical trial. Proceedings of the 43rd Annual Interscience Conference on Antimicrobial Agents and Chemotherapy; September 14-17, 2003; Chicago, IL. Abstract L-739.

Mutnick AH, Enne V, Jones RN. Linezolid resistance since 2001: SENTRY Antimicrobial Surveillance Program. Ann Pharmacother. 2003;37:769-774.

Nannini EC, Pai SR, Singh KV, Murray BE. Activity of tigecycline (GAR-936), a novel glycyclcycline, against enterococci in the mouse peritonitis model. Antimicrob Agents Chemother. 2003;47:529-532.

Nathwani D. Tigecycline: clinical evidence and formulary positioning. Int J Antimicrob Agents. 2005;25:185-192.

Oliva ME, Rekha A, Yellin A, et al; 301 Study Group. A multicenter trial of the efficacy and safety of tigecycline versus imipenem/cilastatin in patients with complicated intra-abdominal infections [Study ID Numbers: 3074A1-301-WW; ClinicalTrials.gov Identifier: NCT00081744]. BMC Infect Dis. 2005;5:88.

Petersen PJ, Bradford PA. Effect of medium age and supplementation with the biocatalytic oxygen-reducing agent oxyrase on in vitro activities of tigecycline against recent clinical isolates. Antimicrob Agents Chemother. 2005;49:3910-3918.

Picazo JJ, Betriu C, Gomez M, Rodriguez-Avial I, Sanchez BA. In vitro activity of tigecycline compared with other antimicrobial agents against recent clinical isolates of methicillin-resistant Staphylococcus aureus. Proceedings of the 43rd Annual Interscience Conference on Antimicrobial Agents and Chemotherapy; September 14-17, 2003; Chicago, IL. Abstract E-1526.

Plowman R. The socioeconomic burden of hospital acquired infection. Euro Surveill. 2000;5:49-50.

Postier RG, Green SL, Klein SR, Ellis-Grosse EJ, Loh E; Tigecycline 200 Study Group. Results of a multicenter, randomized, open-label efficacy and safety study of two doses of tigecycline for complicated skin and skin structure infections in hospitalized patients. Clin Ther. 2004;26:704-714.

Projan SJ. Preclinical pharmacology of GAR-936, a novel glycylcycline antibacterial agent. Pharmacotherapy. 2000;20:219S-223S. 
Raghavan M, Linden PK. Newer treatment options for skin and soft tissue infections. Drugs. 2004;64:1621-1642.

Reynolds R, Potz N; BSAC Working Party on Bacteraemia Isolates in the UK and Eire. Activity of tigecycline against 2206 recent bacteremia isolates in the UK and Eire. Proceedings of the 43rd Annual Interscience Conference on Antimicrobial Agents and Chemotherapy; September 14-17, 2003; Chicago, IL. Abstract E-1532.

Roblin PM, Hammerschlag MR. In vitro activity of GAR-936 against Chlamydia pneumoniae and Chlamydia trachomatis. Int $J$ Antimicrob Agents. 2000;16:61-63.

Sabol K, Patterson JE, Lewis JS 2nd, Owens A, Cadena J, Jorgensen JH. Emergence of daptomycin resistance in Enterococcus faecium during daptomycin therapy. Antimicrob Agents Chemother. 2005;49:1664-1665.

Sacchadinand S, Penn RL, Embil JM, et al. Efficacy and safety of tigecycline monotherapy compared with vancomycin plus aztreonam in patients with complicated skin and skin structure infections: results from a phase 3 , randomized, double-blind trial. Int J Infect Dis. 2005;9:251-261.

Shah PM. The need for new therapeutic agents: what is in the pipeline? Clin Microbiol Infect. 2005;11(Suppl. 3):36-42.

Solomkin JS, Mazuski JE, Baron EJ, et al. Guidelines for the selection of antiinfective agents for complicated intra-abdominal infections. Clin Infect Dis. 2003;37:997-1005.

Stevens DL, Bisno AL, Chambers HF, et al. Practice guidelines for the diagnosis and management of skin and soft-tissue infections. Clin Infect Dis. 2005;41:1373-1406.

Strahilevitz J, Rubinstein E. Novel agents for resistant Gram-positive infections - a review. Int J Infect Dis. 2002;6:S38-S46.

Troy SM, Muralidharan G, Micalizzi M, Mojavarian P, Salacinski L, Raible D. The effects of renal disease on the pharmacokinetics of tigecycline (GAR-936).

Proceedings of the 43rd Annual Interscience Conference on Antimicrobial

Agents and Chemotherapy; September 14-17, 2003; Chicago, IL. Abstract A-22.
US Congress Office of Technology Assessment. Impacts of antibiotic-resistant bacteria. Washington, DC: US Government Printing Office; September 2005. Publication No. OTA-H-629.

Wallace Jr RJ, Brown-Elliott BA, Crist CJ, Mann L, Wilson RW. Comparison of the in vitro activity of the glycylcycline tigecycline (formerly GAR-936) with those of tetracycline, minocycline, and doxycycline against isolates of nontuberculous mycobacteria. Antimicrob Agents Chemother. 2002;46:3164-3167.

Wenzel RP. The antibiotic pipeline - challenges, costs, and values. $\underline{N \text { Engl J }}$ Med. 2004;351:523-526.

Wilson P. Endemic, highly resistant Acinetobacter in the intensive care unit is tigecycline the answer? Clin Microbiol Infect. 2004;10(Suppl. 3):247 (Abstract P938).

Yu H, Mallick R, Weber DJ. Duration of antibiotic treatment in hospitalized patients with complicated skin and skin structure infections (cSSSI): findings from a clinical study comparing tigecycline and vancomycin/aztreonam. Poster presented at: International Society for Pharmacoeconomics and Outcomes Research, 10th Annual Meeting; May 15-18, 2005; Washington, DC. Poster PIN3.

Zhanel GG, Homenuik K, Nichol K, et al. The glycylcyclines: a comparative review with the tetracyclines. Drugs. 2004;64:63-88.

Correspondence: Doris Peter, Core Medical Publishing, 445 Hamilton Avenue, Suite 1102, White Plains, New York, NY 10601, USA or at editor@coreevidence.com 